\title{
Editorial
}

\section{Lesiones abdominales por arma de fuego en el embarazo}

\author{
Dr. Eduardo Vargas Alvarado
}

1. Profesor Emérito de Medicina Legal. Escuela de Medicina, Universidad de Costa Rica

ISSN 0001-6002/2004/46/2/56 Acta Médica Costarricense, $\odot 2004$ Colegio de Médicos y Cirujanos
El auge de la violencia trae la posibilidad de que una mujer embarazada reciba el impacto de un proyectil disparo por arma de fuego en su abdomen. Esto tiene dos aspectos: el quirúrgico y el medicolegal. El primero es muy bien ilustrado por los autores con el caso que presentan del Servicio de Emergencias Quirúrgicas del Hospital San Juan de Dios. El segundo amerita este comentario.

Cuando la lesión se produjo sin voluntad de dañar por parte de quién disparo, pero éste estaba en condiciones de evitarlo, la situación es calificada por los juristas como lesión culposa, y de haberse producido por consecuencia la muerte del producto de la gestación, de aborto culposo, y de haber ocurrido también la de la madre, homicidio culposo.

Es entonces cuando tiene valor, para sentar las responsabilidades del autor del disparo, establecer las siguientes fases clínicas:

Relación topográfica ente la localización del disparo y el compromiso con el cuerpo del feto.

Relación anatomoclínica. Desde el momento de la lesión hubo una cadena de alteraciones clínicas en la madre, sugestivas de aborto.

Relación cronológica. La muerte del producto de la gestación guarda congruencia con la fecha de la herida por proyectil de arma de fuego en el abdomen de la madre.

La medicina fetal ha traído un cambio en el enfoque medicoquirúrgico. En la actualidad, casos como el aquí presentado, donde antes lo único posible era salvar la vida de la madre, ahora permiten también salvar a las dos víctimas: madre e hijo.
ISSN 0001-6002/2004/46/3/112

Acta Médica Costarricense,@2004

Colegio de Médicos y Cirujanos 